\title{
Networks of Global Policy Diffusion: The Introduction of Compulsory Education
}

\author{
Helen Seitzer, Fabian Besche-Truthe, \\ and Michael Windzio
}

\section{Introduction $^{1}$}

Compulsory education is a standard most countries nowadays adhere to. Welfare-states are considered responsible for providing universal access

${ }^{1}$ This chapter is a product of the research conducted in the Collaborative Research Center "Global Dynamics of Social Policy" at the University of Bremen. The center is funded by the Deutsche Forschungsgemeinschaft (DFG, German Research Foundation)_project number 374666841-SFB 1342.

H. Seitzer $(\varangle) \cdot$ F. Besche-Truthe $\cdot$ M. Windzio

SOCIUM, University of Bremen, Bremen, Germany

e-mail: seitzer@uni-bremen.de

F. Besche-Truthe

e-mail: fbesche@uni-bremen.de

M. Windzio

e-mail: mwindzio@uni-bremen.de 
to education (World Conference on Education for All 1990). Education has always played a crucial role in society-it prepares students to contribute to the labor market and society, ensures social order, and permits social mobility at the same time: "Education is prestigious, is thought functional for all sorts of goods, and is seen as both individually and collectively beneficial" (Strang and Meyer 1993, 502). Social status is heavily influenced by education, increasing the demand for institutions of mass education, as it promises social mobility and life-chances otherwise unattainable. In addition, well-organized rational bureaucracies require appropriately qualified employees and citizen (Weymann 2014). In short, education closely corresponds with modernization. However, there are different pathways into modernity (Eisenstadt 1986), which also depend on different cultures and religions. A crucial aspect of education is the transmission of norms and values from one generation to the next. With this, it ensures not only the continuation of traditions but also influences and shapes the persistence of local and national cultures (Morin 2016; Boyer 2018). As a consequence, the content and shape of state-organized education is tied to local culture and practices. At the same time, it is also a result of transnational processes and developments. In this chapter, we elaborate upon the question: what determinants have shaped the global diffusion of compulsory education policies?

Education started to become increasingly important with the rising significance of the individual (Ramirez 1989) and with globalization trends (Griffiths and Imre 2013). This leads us to the assumption that state-regulated education may not only vary in content between cultures but also have varying degrees of significance for societies, resulting in varying time points of compulsory education introduction. Our hypothesis, therefore, is that culture influenced the introduction of compulsory education around the globe. Despite cultural differences, however, modern education systems are remarkably similar. Most schools have two- or three-tier systems (primary, secondary, and tertiary), class structures divided by age-group and front-facing instructions, not to mention the focus on mathematics, reading, sciences, history, and physical and arts education, just to name a few (Anderson-Levitt 2003). Yet, the actual content of these curricula might differ between cultures. The long-term 
trend towards isomorphism continues despite remarkable global differences between cultures (Henrich 2020). This perspective, but especially the inclusion of shared cultural traits as a pathway of diffusion, has been ignored in research on the development of social policy for far too long.

State-organized education is the outcome of religious, economic, and political mechanisms that drive a rationalized society and state, secularizing the organizational and institutional rules of the individual's membership in these units (Weber 1972; Weymann 2014). Education allows nation states to shift the focus to the individual, which is now responsible to take its role in differentiated units of a complex society. It provides the cognitive basis for a (post-)industrialized state's rational administration. Secularization and Western rationalization originated from a particular cultural development in the Occident (Weber 1972), whereas other areas in the world followed different cultural pathways into modernity (Eisenstadt 1986), which might also affect the establishment of educational institutions such as compulsory education.

However, one has to keep in mind that culture is not the only influential factor on the introduction of social policies such as education. Diffusion research has shown that the transformation and, especially, diffusion of policies are highly dependent on countries' opportunities for interaction. Therefore, taking a network perspective to study the introduction of compulsory education should not come as a surprise. The diffusion of compulsory education is, in our perspective, dependent on the ties and networks between countries. Therefore, in this chapter, we implement a network diffusion approach by including the exposure to countries that have already adopted compulsory education. The connections in the distinct networks determine the exposure and are, in some cases, volatile over time but also changing in tie strength. We construct the ties between countries through connections of trade, colonial legacies, or spatial proximity.

Furthermore, we include a network of shared cultural characteristics between countries to test the influence of culture on the diffusion of education policy. According to our approach, countries are more closely tied to each other when they share more cultural characteristics. How to define "culture," how culture influences individual behavior, 
and how cultures differ around the world, are important but controversial issues in the social sciences (Anderson-Levitt 2012). In our view, "culture" essentially signifies a shared understanding of reality, which is among others represented by beliefs as to how society-and its institutions - should be structured and organized. Furthermore, aspects such as religion, language, and societal values make up the complex concept of "culture" differentiating between social groups. Long-term historical path dependencies led to remarkable differences between global cultures (Weber 1972), and these differences are still important today (Henrich 2020). Our approach to analyze "cultural spheres" provides a non-essentialist concept of culture. It results in a two-mode network approach which provides fuzzy-set clusters with overlapping boundaries and displays a changing structure and membership in these cultural clusters over time (Windzio and Martens 2021). However, we will argue that culture closely relates to other dimensions of multiplex network ties, such as spatial proximity, colonial past, and global trade. If we want to test whether cultural similarity is a relevant "pipe structure" of social policy diffusion, which is in our case compulsory education, we must take into account these correlated networks. Hence, the analyses in this chapter test the diffusion effects of the respective networks against each other. Do we still find effects of cultural similarity on the global diffusion of compulsory education after controlling for colonial history, global trade, and spatial proximity? Or is the diffusion rather a result of a combination of multiplex networks connecting countries globally?

\section{Theory}

Policy diffusion as a general umbrella term describes multiple mechanisms through which policies travel from one country to another. The literature mentions, e.g., (1) learning, (2) competition, (3) imitation, or (4) coercion (Dobbin et al. 2007; Obinger et al. 2013). Which of the mechanisms is at work in education policy, however, is difficult to discern using a macro quantitative design. Nevertheless, there are multiple theoretical approaches, exploring reasons for the diffusion of compulsory education. A common approach is Meyer and colleague's World Society 
theory (Meyer et al. 1997). Another, related explanation can be found in "critical cultural political economy" (CCPE) (Dale 2000) or in Marxist functionalist theories such as the World Systems Approach (Wallerstein 2004; Griffiths and Imre 2013). We start our theoretical considerations with World Society theory, enhance it with insights from research on global "cultural spheres" and contrast this view with the CCPE approach.

In the globalized world society, individuals and organizations are interested in common institutionalized standards, especially when they interact across different national institutions. Aided by powerful Western states, modern, Western bureaucracies tend to spread around the world (Meyer et al. 1997) because International Organizations (IOs) require predictable organizational standards. World Society revolves around the construction of actor-hood, identity, and legitimization of the state and non-state actors involved in policymaking. In order to gain legitimacy, these actors tend to integrate commonly accepted models or concepts such as human rights or even, the concept of a state itself into their own system. Recognition of statehood by external actors with scientific and professional authority such as other states, IOs, or other non-state actors has always been a crucial dimension of the Western political system. This element, according to Meyer and colleagues, has led to the development of a set of norms and standards, a global culture so to speak, recognized and influenced by all parties of world society (Meyer et al. 1997). The implementation of these norms and standards grants legitimization. Accepting this global culture, however, can be much more a performative act than an integration of these norms in the local belief system (Steiner-Khamsi 2000) —it can be just "myth and ceremony" (Meyer and Rowan 1977). The participation in International Large Scale Assessments, for example, is an often used tool to gain attention, gather funds such as developmental aid, or simply legitimize a country further in the eyes of other nation states (e.g., Kijima 2015). Deviations from the general standardized systems as well as failed implementation are not always a contradiction to the common model. Rather, the confirmation of these deviations as irregular further validates the existence of a common model. However, non-compliance with the implicit rules can have serious negative consequences as well. The non-participation in tests 
like PISA is penalized: The Human Capital Index by the World Banka scale playing the role as a rationalized other with scientific authority in this instance-is negatively affected for non-participating countries (Liu and Steiner-Khamsi 2020). World society induces isomorphism among education systems, of which compulsory education is a crucial part (Meyer et al. 1997).

The acceptance of a common set of standards makes interactions easier and increases the chances of ties such as trade, which might be beneficial for some states. As a consequence, the perception of national culture and identity became important issues in the domestic politics in many Western countries but also at the global level (Fukuyama 2018). The adoption of policies according to this model requires an understanding of similarities between the systems, which further increases interaction and finally diffusion (Strang and Meyer 1993).

The idea of a world society lends itself to explain the isomorphism of countries' institutions and the frequent proclamation of policy diffusion we see in educational research. Nevertheless, the diffusion process of compulsory education might be shaped and moderated by different cultures in the world. We do not regard cultures as stable entities here but as embedded in a network of socially constructed elements. There is no objective point of reference between different cultures. Aspects of values, attitudes and social behavior in one culture, such as the degree of individualism or collectivism, are just distributed differently in comparison to other cultures. In ontological terms, the individualism in the West gains its existence only in comparison to other cultures that are supposed to be less individualistic. As we know from social network research, components of cultures refer to one another like fuzzy-set clusters and give meaning to each other (Emirbayer and Goodwin 1994; Emirbayer 1997, 299). Here, we are considering additional approaches as influential, especially to account for other globalizing influences than culture, in particular economic aspects. Dale (2000) puts special emphasis on the economy, in that the education systems we see today are not only influenced by national culture but also by capitalism as an economic system. Although the economic system is also an outcome of specific cultural developments (Weber 1972), Critical Cultural Political Economy 
places emphasis on interrelations between countries shaped by the capitalist system at large. Today's education system prepares students for the needs of the labor market and graduates from education systems are set on a path to repeat and further stabilize the system. In this approach, capitalism is regarded more as a causal force, responsible for shaping education, rather than an outcome (Dale 2000; Robertson and Dale 2015). Knowledge, rather than production, translates into economic success (Dale 2005). Here too, diffusion of social policy occurs, albeit for different reasons than assumed by world society theory. Culture and the need for legitimization are relevant factors in the diffusion of education policy, but CCPE might very well be correct in highlighting the specific influence of the economy in this process.

According to the view that economic processes influence education systems, the production of goods and services determines a society's economic structure and the degree in which information is processed, since information is what modern service economies are about (Hidalgo 2015). Even though global economies are based on the division of labor and comparative cost advantages, implying differences in their economic structure, global trade requires common standards with respect to quality assessment, commercial accounting, and legal issues regarding the respective transaction. If economic transactions go beyond economic exploitation, as we know from colonial dependencies which often came along with a transfer of institutions, trade partners are becoming more closely aligned. Extensive trade between nation states extends communication and can accelerate economic progress, which is why we assume that countries linked in the network of global trade often introduced compulsory education in similar historical periods. In other words, strengthened economic intersection increases the need for similar institutionalizations of education systems.

Flipping the argument, we might see that similar institutionalization might be one pre-requisite for diffusion. We assume that colonial legacies might prove influential through building path dependency in the institutionalization. Colonial ties between two countries usually imply asymmetric relationships of economic exploitation. Yet, these ties show possible avenues for a colonial power imposing at least some of its institutions upon the colony. This "imperial diffusion" (Kuhlmann et al. 2020) 
might have been prevalent in the introduction of compulsory education to pacify conflicts. Additionally, we suspect the influence does not disappear after colonization ends. Former colonies are still exposed to the educational institutions of their colonizers. These colonizers prove to still be influential through development aid, for example (Shields and Menashy 2017), or simply because they are a salient reference country (Dobbin et al. 2007, 453). Thus, compulsory education might diffuse also via networks of colonial legacies. To the contrary, it can also be as equally true that local actors strongly repel institutionalization of education following a Western model (Craig 1981, 192).

Finally, the basic assumption in policy diffusion research is that spatial proximity strongly facilitates diffusion. Of course, we agree with the view that "Space is more than Geography" (Beck et al. 2006), and spatial proximity itself is not a mechanism that could explain policy diffusion. Rather, spatial proximity is an indicator of cognitive, social, cultural, and institutional similarity. On the one hand, this indicator is far from being perfect, particularly at the margins of a "cultural sphere" (Windzio and Martens 2021). On the other hand, the determination of spatial distances is comparatively simple and intuitively easy to follow. We can measure spatial proximity itself with less error than the "cultural spheres". We expect spatial distance to have a "retarding" effect on policy diffusion because the opportunity to meet decreases with increasing distance. Possibilities for contact depend on specific mechanisms that might be correlated with spatial proximity. Accordingly, proximity itself is not a mechanism but has the advantage of a simple and precise measurement compared to more complex constructs, such as cultural similarity (Windzio and Martens 2021). Thus, in the following, we empirically test the influence of these different network dimensions on the diffusion of compulsory education and control for levels of democratization and GDP per capita in order to take economic and political heterogeneity between countries into account. 


\section{Data and Methods}

In this chapter, we analyze the worldwide diffusion of compulsory education. We coded the year of the adoption of first regulation, making education mandatory for the majority of all children in the respective country. For most cases this means the attendance of state-regulated schools. We are interested in the moment when the state intervenes in the education of children and mandates education to be conducted. We, therefore, code the first de jure introduction and disregard actual implementation as well as abolitions. For example, a law enacted in 2000 makes school compulsory in Djibouti, implying school attendance. However, 1 in 5 children of primary school age is not attending school. ${ }^{2}$ Another example is Singapore, where high enrollment rates precede compulsory education: Here, compulsory schooling was only enacted in 2003 with enrollment rates already reaching more than $90 \%$, even 20 years prior to that (Tan 2010). Our data collection is based on the "World Education Encyclopedia" by Marlow-Ferguson (2002) and the Bloomsbury "Education around the World Series" (e.g., Brock and Alexiandou 2013). We expand the data with extensive research on concrete laws and a myriad of additional secondary sources.

Lastly, we tried to code according to geographic region as best as possible. North Macedonia, for example, is coded similarly to Serbia and Slovenia because at the time of adoption it was part of the Kingdom of Serbs, Croats, and Slovenes and only later gained independence (Spasenović et al. 2015). Croatia, on the other hand, introduced compulsory education earlier. For federal states, we decided to code the first law on compulsory schooling enacted by the central authority. If this was not possible, we coded the first time of adoption of compulsory schooling of the first political entity within the territory, for example, this included Tasmania in 1868 for Australia.

Figure 3.1 shows the number of introductions per year (yellow) as well as the cumulative introduction rate of compulsory education (red). The figure shows that there are only a few points in time where multiple introductions took place in the same year, for example, around 1920.

${ }^{2}$ https://www.unicef.org/djibouti/education. 


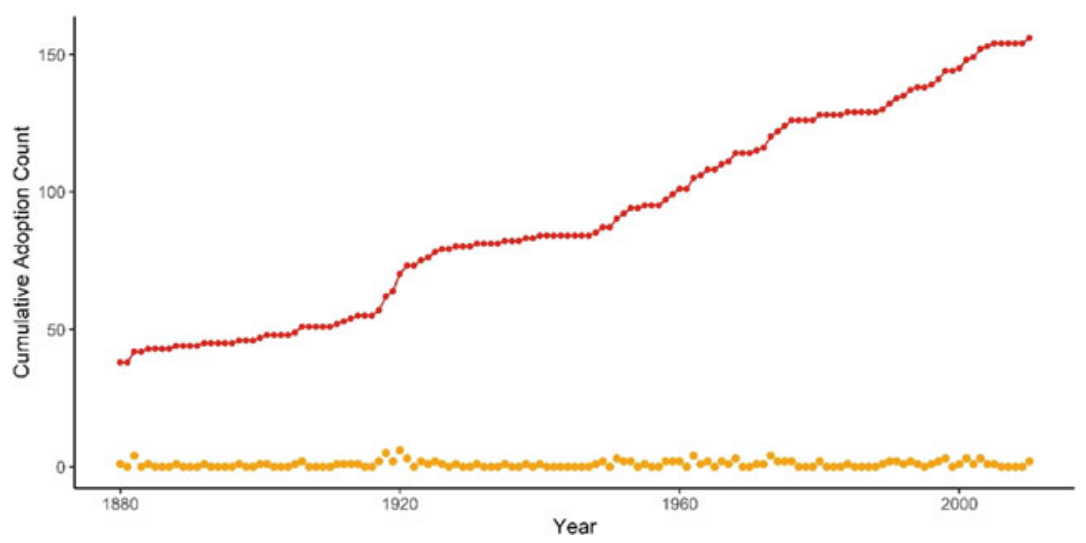

Fig. 3.1 Cumulative introduction of compulsory education

Consequently, the cumulative introduction function (red dotted line) is increasing relatively linear. We, therefore, do not assume a strong dependence on certain time periods over the course of history.

We assume diffusion through networks of shared cultural similarity (membership in cultural spheres), colonial legacies, trade, and geographical proximity from 1880 to 2010 . For this purpose, we analyze data on cultural characteristics of $N=164$ countries, including indicators of political liberties, rule of law, gender roles, dominant religion, language group, government ideology, classification of civilization, and colonial past (Besche-Truthe et al. 2020). We generated quartiles of continuous measurements, e.g., for the index of gender relations, in order to get discrete categories for a valued two-mode network. If two countries share a characteristic, they connect to each other in the network. Most countries establish several relations, for example, by sharing the same language group and the largest religious group. The higher the number of ties in this network, the closer the cultural proximity between two countries. Rather than homogenous clusters and clear-cut "fault lines," this method yields a network of "cultural spheres" with relations of varying intensity between countries. The cultural spheres network is time-varying due to the time-varying measurement of most cultural indicators. Elsewhere, we used the metaphor of a "pipe structure" as the underlying structure of the diffusion process (Windzio and Martens 2021), where the "pipe 
diameter" is the number of ties in a dyad and thus, the degree of similarity of two countries. Larger pipe diameters lead to a higher weight of a tie and indicate higher "cultural exposure" of country A to country B. This might increase the likelihood of "contagion", given that a specific policy has not yet been adopted in one of the two countries. We regard networks of cultural spheres, spatial proximity, global trade, and colonial legacies as the underlying pipe structures of the diffusion process. In the spatial proximity network, countries' ties are weighted by the inverse of the distance of their capitals, and it is therefore the only timeindependent network. Trade and colonial legacies, on the other hand, differ over time, where the former shows the logarithmized sum of the value of all traded goods between two countries. For the latter, we utilize two different operationalizations of colonial legacy. First, we weigh the influence of multiple former colonizers against each other. Second, we assume an overall receding influence after decolonization, while assuming the influence of two colonizers might be stronger than for entities with just one colonizer (for a detailed description of the data, see Chapter 1 in this volume). We report the estimation using the latter operationalization in the appendix.

Missing data in our control variable GDP per capita from Varieties of Democracy (Inklaar et al. 2018) was interpolated with a logistic function to account for the nonlinear rise of GDP. Where there was no data from the first observation in 1880, the data from the income group of the respective countries was used as a starting point. The values were transferred onto a different scale to represent the share of GDP at the respective time points to the maximum value achieved during our time of observation. The data was then transformed onto a logit scale, interpolated linearly, and transformed back through an inverse logit function and onto the original scale. This procedure produces the rise of GDP in a logistic shape, providing a more realistic use of the indicator as a linear interpolation would. The democracy index stems from the V-Dem Project (Coppedge et al. 2019). Here, missing data points were interpolated linearly. For our analysis, we utilize the $R$ package netdiffuseR (Vega Yon and Valente 2021) which defines exposure as the share of $j$ adopters in the ego-centered network of node $i(i \neq j)$ at time $t$ and is supposed to affect the adoption rate between $t$ and $t+1$ (Valente 
1995). If a country is only connected to other countries that already have adopted compulsory schooling, exposure is 1. If none have adopted, exposure is 0 (for details of these concepts, see Chapter 1 in this volume). The introduction of compulsory schooling (no compulsory schooling = 0 and introduction of compulsory schooling $=1$ ) during the window of observation is the dependent variable in our discrete-time logistic hazard model. Once a country has introduced compulsory schooling, it drops out of the risk set. Introductions after 2010 are right-censored, adoptions before the window of observation begins (before 1880) are not considered in the risks set but contribute to the network-exposure of countries that have not yet adopted. Since compulsory education is an older social policy than other policy fields dealt with in this volume, we do not consider the same number of countries in the regression, as some countries had introduced compulsory education before 1880. Thus, from the initial set of 164 we only keep 117 countries. However, the full set of countries contributed to the estimation of exposure. Further explanations on the data and analysis can be found in the introductory chapter of this volume.

\section{Results}

To answer the question of the influence of different networks on the diffusion and consequently introduction of compulsory education, we first employed a diffusion model to estimate the effects of contagion in different networks. These coefficients were then used in a time-discrete logistic hazard model, estimating the influence of contagion on the final outcome, the adoption of compulsory education. Time is modeled as a step function, which means that for every time period of around 25 years, a new constant is assumed. In doing so, we account for unobserved heterogeneity that develops over time. Figure 3.2 shows the spread of compulsory education around the globe. The map indicates that among the first countries to implement compulsory education, Western or English-speaking countries are very prominent. Additionally, some Middle and South American countries can be counted among the early adopters. 


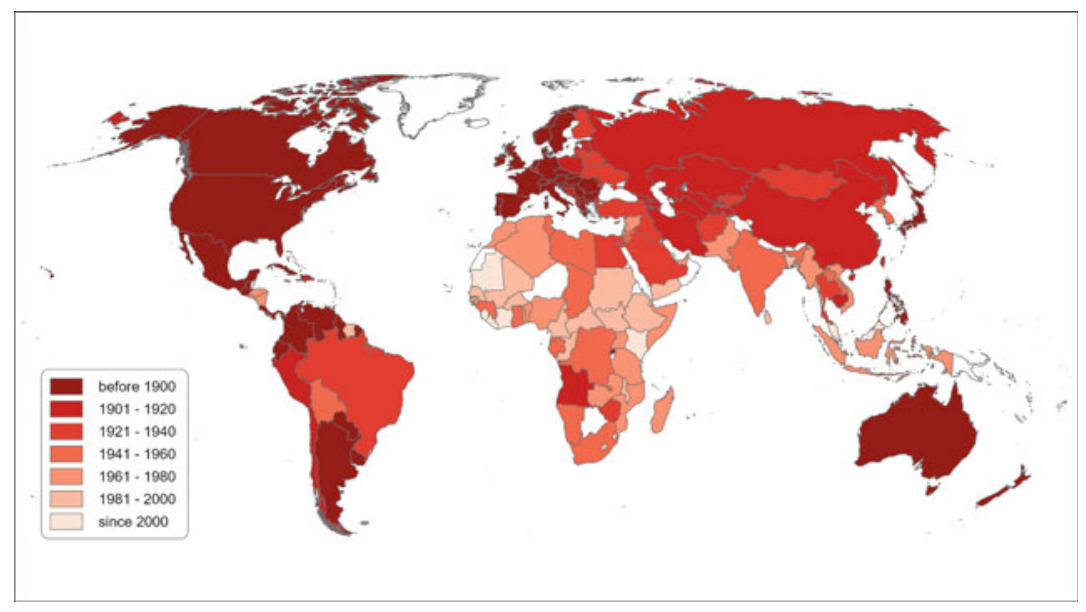

Fig. 3.2 The global diffusion of compulsory education

Table 3.1 shows the outcomes of the logistic hazard models. First, we estimated the time rates, then included measures for GDP per capita, a democratization index, and the networks, added step wise. Exposure in the networks of cultural spheres as well as trade and geographical proximity is estimated with a one-year lag. The final regression coefficients are corrected with a standard error correction for clustered standard errors, to account for times when countries to be known as separate entities today, were one political unit. This implicates that during these times adoptions could have been dependent on the political overlap, hence the correction of standard errors. The coefficients were transformed to hazard ratios. The interpretation, therefore, goes as follows: Coefficients greater than 1 indicate a positive effect while coefficients smaller than 1 indicate a negative effect of the variable in question. The hazard ratios for the networks represent the odds of adopting compulsory education, given the exposure though the network in question to countries, who have already adopted compulsory education. 
Table 3.1 The introduction of compulsory education in $N=117$ countries

\begin{tabular}{|c|c|c|c|c|}
\hline & (1) & (2) & (3) & (4) \\
\hline 1880-1914 & $0.001^{* * *}$ & $0.001^{* * *}$ & $0.001^{* * *}$ & $0.001^{* * *}$ \\
\hline $1915-1929$ & $0.002^{* * *}$ & $0.002^{* * *}$ & $0.002^{* * *}$ & $0.001^{* * *}$ \\
\hline 1930-1954 & $0.001^{* * *}$ & $0.001^{* * *}$ & $0.001^{* * *}$ & $0.0005^{* * *}$ \\
\hline 1955-1979 & $0.001^{* * *}$ & $0.001^{* * *}$ & $0.001^{* * *}$ & $0.0004^{* * *}$ \\
\hline $1980-2010$ & $0.001^{* * *}$ & $0.001^{* * *}$ & $0.001^{* * *}$ & $0.0002^{* * *}$ \\
\hline $\begin{array}{l}\text { trade existence }(=1 \text {, else } \\
\quad=0)\end{array}$ & & & $5.469^{* * *}$ & $4.124^{\star * *}$ \\
\hline $\begin{array}{l}\text { GDP per } \\
\text { capita/US } \$ 10,000\end{array}$ & 1.020 & 1.021 & 1.020 & 0.977 \\
\hline $\begin{array}{l}\text { democratization } \\
\text { networks }\end{array}$ & 1.069 & 1.065 & 0.995 & 1.027 \\
\hline $\begin{array}{l}\text { cultural spheres netw.: } \\
\text { w. exposure } \\
\text { (lag } 1 \text { year) }\end{array}$ & $128.387^{* * *}$ & $136.015^{* * *}$ & $26.357^{\star *}$ & 1.349 \\
\hline $\begin{array}{l}\text { colonies netw.: w. } \\
\text { exposure }\end{array}$ & & 1.213 & 1.344 & 1.151 \\
\hline $\begin{array}{l}\text { trade netw.: w. exposure } \\
\text { (lag } 1 \text { year) }\end{array}$ & & & 0.843 & 0.744 \\
\hline $\begin{array}{l}\text { spatial proximity netw.: } \\
\text { w. exposure } \\
\text { (lag } 1 \text { year) }\end{array}$ & & & & $127.716^{* * *}$ \\
\hline Observations & 8614 & 8614 & 8614 & 8614 \\
\hline Log Likelihood & -550.627 & -550.401 & -534.053 & -524.384 \\
\hline Akaike Inf. Crit & 1117.254 & 1118.802 & 1090.107 & 1072.769 \\
\hline
\end{tabular}

Note ${ }^{+} p<0.1 ;{ }^{*} p<0.05 ;{ }^{* *} p<0.01 ;{ }^{* *} p<0.001$

Regarding the control variables neither the GDP per Capita nor the democratization index are significant in any of the included models. Interestingly, the cultural spheres network is significant and positive for three of the four models. Cultural similarity, therefore, significantly increases the odds of adopting compulsory education. The colonial legacies network as well as the trade network show insignificant effects; exposure in these networks does not have a significant impact on the adoption of compulsory education. Geographical proximity, on the other hand, has a positive impact. In addition to its significant and positive coefficient, geographical proximity diminishes the cultural spheres term's coefficient to non-significance.

Accordingly, in Models (1) to (3) there is no effect of colonial legacies or ties in the global trade network, whereas the effect of ties in 
the cultural spheres network is positive, strong, and highly significant. Modeling an overall receding influence via linkages with former hegemons shows a significant positive influence of the colonial legacy network at first sight (see Table 3.2 in Appendix). However, when excluding territories which have been part of the USSR when they introduced compulsory education, the effect vanishes. ${ }^{3}$ Hence, we conclude that, regardless of the operationalization, colonial rule and legacies do not have an overall effect, but rather, affect isolated cases of imperial diffusion. However, post-colonial links are not significant "pipes" through which compulsory education policy diffuses.

After controlling for spatial proximity, the strong effect of the cultural spheres network vanishes which indicates that exposure in both networks is highly correlated. We should not conclude from these results that spatial proximity is the only crucial factor for diffusion of compulsory education. Simply for the reason, that spatial proximity itself cannot be a mechanism of diffusion, but rather, is a catch-all indicator. Spatial proximity, thereby also, indicates similarity in institutional forms and culture. Even though we captured the influence of culture by controlling for our cultural spheres network, our cultural spheres are construed by theoretical considerations and particular methods (Windzio and Martens 2021; Besche-Truthe et al. 2020). In contrast to the simple measurement of spatial proximity, the complex procedure to generate cultural spheres is prone to measurement error, which is certainly the reason why the strong effect of the latter disappears after controlling for the former.

\section{Conclusion}

In this paper, we tested the impact of four networks of potential policy diffusion on the implementation of compulsory education around the globe. Education, as a crucial part of today's welfare state, is influenced not only by national but also international forces. When looking at modes of diffusion for education policy, culture is a factor that has previously rarely been considered. To test its impact, we utilize a projected

${ }^{3}$ Model not included. 
two-mode network of different cultural characteristics such as language, religion, and gender roles. Culture is influencing education, as education does not only prepare students for the labor market but also ensures the continuation of local values and traditions. Similar educational standards promote communication and interaction between countries, increasing the opportunities of policy diffusion. Similarly, a trade network as well as colonial legacies as channels for policy diffusion have been considered as well. Additionally, a network of geographical proximity, GDP per capita, and a democratization index were considered as control variables.

The results show, that even when controlling for democratization and GDP per capita, culture does indeed matter. Exposure through the cultural similarity network was consistently significant and positive, until the geographical proximity was brought in. Neither colonial legacies nor trade could produce significant results, even without controlling for cultural spheres. This is an unexpected outcome, as one could assume that similar educational standards might emerge through the need of standardization for trade. Unfortunately, we do not assess imbalances in trade or goods. In any case, trade as a "pipe structure" of policy diffusion was not proven significantly influential. Similarly, colonial relationships clearly show that they did not influence the diffusion of compulsory education. The suppression of the cultural spheres effect through the exposure effect from the geographical proximity network is, however, not as surprising. The correlation of exposure in these very networks is 0.919 (see Chapter 1 in this volume), signifying that closely located countries often share similar cultural traits, explaining the correlation between the networks.

In the end, this result is not easily interpretable. On the one hand, the effect of the cultural spheres network on diffusion vanishes after controlling for spatial proximity, on the other hand, researchers often regard spatial proximity just as an indicator of mechanisms that are often embedded in communication, social interaction, and culture. Since the measurement of cultural spheres is much more complex, and the construct itself depends on contingent decisions made by the researchers, the resulting measurement error is a crucial disadvantage for the cultural 
spheres network, when compared with spatial proximity and testing the significance of influences on diffusion. We should, therefore, not conclude that the network of cultural proximity has no influence, and spatial proximity is the crucial determinant because of the measurement error and the lack of theoretical meaning of spatial proximity. In other words, a theoretical explanation by spatial proximity cannot be done independently of other, more social or cognitive arguments (Beck et al. 2006).

As discussed previously, the membership in cultural spheres does influence the introduction of compulsory education, at least to some degree. This result goes in line with our theoretical assumption that education is not only derived from singular national factors and history but that legitimization and adaption to external units is an important aspect of policy diffusion. The increasing isomorphism of education systems or at least the global agreement that education should be accessible for all and, therefore, compulsory, are determined by cultural and geographical proximity. The fact that neither the trade network nor GDP per capita showed significant results, do not negate the economic influence education policy is subjected to, but rather, signify that these measures are not indicative of this influence. When GDP per capita and trade are taken out of the analysis, the model fit declines. ${ }^{4}$ Research on education policy diffusion should not ignore economic factors but should include cultural factors in addition to the "usual suspects." We do not attempt to disprove Robertson and Dale's theoretical approach; we simply support the development of this hypothesis further and consider culture in addition to economic factors with a more substantial approach than previous theories do.

Culture is an explanation for the global diffusion of compulsory education in line with sociological neo-institutionalism. This theory argues in favor of a global diffusion of institutional forms and

${ }^{4}$ Model not included. 
content within education. As argued in the section on theory, neoinstitutionalism expects a global spread of Western bureaucratic institutions, even though their adoption seems to be in some countries rather myth and ceremony than a serious implementation (Meyer and Rowan 1977). In addition, this process of diffusion is shaped by cultural spheres. These cultural spheres, however, are considerably correlated with spatial proximity between countries. Future research should systematically account for the interaction of network-exposure and historical time periods in order to test, if or how the respective network effects change over time.

\section{Limitations}

As any other study, this analysis has its limitations. First, the quality of data dating back to 1880 might influence the result. The difficulty of modeling longitudinal analyses with a changing country sample for the same geographical area should be kept in mind. Units such as the USSR as well as Austria-Hungary, for example, have been taken into account by correcting for clustered standard errors. Nevertheless, this method has its weaknesses too. Second, as briefly discussed, education policy is highly shaped by the activities of International Organization such as the OECD. A network of membership in international organizations could have been added to the analysis to account for this diffusion channel as well, but this effect was left for future researchers to discover. Despite these limitations, we are convinced that the model presented here still demonstrates interesting results, as it reveals not only the strong influence of culture on education but also shows the weak influence of democratization and GDP on the adoption of compulsory education.

\section{Appendix}

See Table 3.2. 
Table 3.2 The introduction of compulsory education in $N=117$ countriesnon-normalized exposure in colonial legacies network

\begin{tabular}{|c|c|c|c|c|}
\hline & (1) & (2) & (3) & (4) \\
\hline $1880-1914$ & $0.001^{* * *}$ & $0.001^{* * *}$ & $0.001^{* * *}$ & $0.0004^{* * *}$ \\
\hline 1915-1929 & $0.002^{* * *}$ & $0.002^{* * *}$ & $0.002^{* * *}$ & $0.001^{* * *}$ \\
\hline 1930-1954 & $0.001^{* * *}$ & $0.001^{* * *}$ & $0.001^{* * *}$ & $0.0003^{* \star *}$ \\
\hline 1955-1979 & $0.001^{* * *}$ & $0.001^{* * *}$ & $0.0004^{* * *}$ & $0.0002^{* * *}$ \\
\hline 1980-2010 & $0.001^{* * *}$ & $0.001^{* * *}$ & $0.0004^{* * *}$ & $0.0001^{* * *}$ \\
\hline $\begin{array}{l}\text { state existed }(=1, \text { else }= \\
0)\end{array}$ & & & $6.836^{* * *}$ & $5.123^{* * *}$ \\
\hline $\begin{array}{l}\text { GDP per capita } \\
\text { /US } \$ 10,000\end{array}$ & 1.020 & 1.020 & 1.018 & 0.976 \\
\hline $\begin{array}{l}\text { democratization } \\
\text { networks }\end{array}$ & 1.069 & 1.069 & 0.995 & 1.025 \\
\hline $\begin{array}{l}\text { cultural spheres netw.: } \\
\text { W. exposure } \\
\text { (lag } 1 \text { year) }\end{array}$ & $128.387^{* * *}$ & $129.283^{* * *}$ & $36.141^{* *}$ & 2.059 \\
\hline $\begin{array}{l}\text { colonies netw.: w } \\
\text { exposure }\end{array}$ & & 1.007 & $1.666^{*}$ & $1.586^{*}$ \\
\hline non-normalized & & & & \\
\hline $\begin{array}{l}\text { trade netw.: w. exposure } \\
\text { (lag } 1 \text { year) }\end{array}$ & & & 0.864 & 0.758 \\
\hline $\begin{array}{l}\text { spatial proximity netw.: } \\
\text { w. exposure } \\
\text { (lag } 1 \text { year) }\end{array}$ & & & & $113.730^{* * *}$ \\
\hline Observations & 8614 & 8614 & 8614 & 8614 \\
\hline Log Likelihood & -550.627 & -550.627 & -532.155 & -522.491 \\
\hline Akaike Inf. Crit & 1117.254 & 1119.254 & 1086.309 & 1068.982 \\
\hline
\end{tabular}

Note ${ }^{+} p<0.1 ;{ }^{*} p<0.05 ;{ }^{* *} p<0.01 ;{ }^{* *} p<0.001$

\section{Literature}

Anderson-Levitt, Kathryn M. 2003. “A World Culture of Schooling?” In Local Meanings, Global Schooling: Anthropology and World Culture Theory, edited by Kathryn M. Anderson-Levitt, 1-41. New York: Palgrave Macmillan.

Anderson-Levitt, Kathryn M., eds. 2012. Anthropologies of Education: A Global Guide to Ethnographic Studies of Learning and Schooling. New York: Berghahn Books.

Beck, Nathaniel, Kristian S. Gleditsch, and Kyle Beardsley. 2006. "Space Is More Than Geography: Using Spatial Econometrics in the Study of Political Economy." International Studies Quarterly 50 (1): 27-44. 
Besche-Truthe, Fabian, Helen Seitzer, and Michael Windzio. 2020. "Cultural Spheres-Creating a Dyadic Dataset of Cultural Proximity.” SFB 1342 Technical Paper Series 5. Bremen.

Boyer, Pascal. 2018. Minds Make Societies: How Cognition Explains the World Humans Create. New Haven: Yale University Press.

Brock, Colin, and Nafsika Alexiandou. 2013. Education Around the World: A Comparative Introduction. Education Around the World Series. London: Bloomsbury Academia.

Craig, John E. 1981. "Chapter 4: The Expansion of Education." Review of Research in Education 9 (1): 151-213.

Coppedge, Michael, John Gerring, Carl H. Knutsen, Staffan I. Lindberg, Jan Teorell, David Altman, Michael Bernhard, et al. 2019. "V-Dem Codebook v9": Varieties of Democracy (V-Dem) Project.

Dale, Roger. 2000. "Globalization and Education: Demonstrating a 'Common World Educational Culture' or Locating a 'Globally Structured Educational Agenda'?" Comparative Education Review 50 (4): 427-448.

Dale, Roger. 2005. "Globalisation, Knowledge Economy and Comparative Education.” Comparative Education 41 (2): 117-149.

Dobbin, Frank, Beth Simmons, and Geoffrey Garrett. 2007. "The Global Diffusion of Public Policies: Social Construction, Coercion, Competition, or Learning?" Annual Review of Sociology 33 (1): 449-472.

Eisenstadt, Shmuel N. 1986. "The Axial Age Breakthroughs-Their Characteristics and Origins." In The Origins and Diversity of Axial Age Civilizations, edited by Shmuel N. Eisenstadt, 1-29. Albany: State University of New York Press.

Emirbayer, Mustafa. 1997. "Manifesto for a Relational Sociology." American Journal of Sociology 103 (2): 281-317.

Emirbayer, Mustafa, and Jeff Goodwin. 1994. "Network Analysis, Culture, and the Problem of Agency." American Journal of Sociology 99 (6): 1411-1454.

Fukuyama, Francis. 2018. Identity: The Demand for Dignity and the Politics of Resentment. New York: Farrar Straus and Giroux.

Griffiths, Tom G., and Robert Imre. 2013. Mass Education, Global Capital, and the World: The Theoretical Lenses of István Mészáros and Immanuel Wallerstein. New York, NY: Palgrave Macmillan.

Henrich, Joseph. 2020. The Weirdest People in the World: How the West Became Psychologically Peculiar and Particularly Prosperous. London: Allen Lane.

Hidalgo, César A. 2015. Why Information Grows: The Evolution of Order, from Atoms to Economies. London: Allen Lane. 
Inklaar, Robert, Harmen de Jong, Jutta Bolt, and Jan van Zanden. 2018. "Rebasing 'Maddison': New Income Comparisons and the Shape of LongRun Economic Development." GDC Research Memorandum GD-174. Last accessed March 24, 2021. https://ideas.repec.org/p/gro/rugggd/gd-174. html.

Kijima, Rie. 2015. "Why Participate? Cross-National Assessments and Foreign Aid to Education." In The Impact of International Achievement Studies on National Education Policymaking, edited by Alexander W. Wiseman, 35-61. Emerald Group Publishing.

Kuhlmann, Johanna, Delia González de Reufels, Klaus Schlichte, and Frank Nullmeier, 2020. "How Social Policy Travels: A Refined Model of Diffusion." Global Social Policy 20 (1): 80-96.

Liu, Ji, and Gita Steiner-Khamsi. 2020. "Human Capital Index and the Hidden Penalty for Non-Participation in ILSAs." International Journal of Educational Development 73 (March).

Marlow-Ferguson, Rebecca. 2002. World Education Encyclopedia: A Survey of Educational Systems Worldwide. Detroit: Gale Group.

Meyer, John W., John Boli, George M. Thomas, and Francisco O. Ramirez. 1997. "World Society and the Nation-State." American Journal of Sociology 103 (1): 144-181.

Meyer, John W., and Brian Rowan. 1977. "Institutionalized Organizations: Formal Structure as Myth and Ceremony." American Journal of Sociology 83 (2): 340-363.

Morin, Olivier. 2016. How Traditions Live and Die: Foundations of Human Interaction. New York: Oxford University Press.

Obinger, Herbert, Carina Schmitt, and Peter Starke. 2013. "Policy Diffusion and Policy Transfer in Comparative Welfare State Research." Social Policy \& Administration 47: 111-129.

Ramirez, Francisco O. 1989. "Reconstituting Children: Extension of Personhood and Citizenship." In Social Structure and Aging: Age Structuring in Comparative Perspective, edited by David I. Kertzer and K. W. Schaie, 143-165. Hillsdale, NJ: L. Erlbaum Associates.

Robertson, Susan L., and Roger Dale. 2015. "Towards a "Critical Cultural Political Economy' Account of the Globalising of Education." Globalisation, Societies and Education 13 (1): 149-170.

Shields, Robin, and Francine Menashy. 2017. "The Network of Bilateral Aid to Education 2005-2015." International Journal of Educational Development 64: 74-80. 
Spasenović, Vera, Hebib Emina, and Slavica Maksić. 2015. "Serbia." In The

Education Systems of Europe, edited by Wolfgang Hörner, Hans Döbert, Lutz

R. Reuter, and Botho von Kopp. Cham: Springer.

Steiner-Khamsi, Gita. 2000. "Transferring Education, Displacing Reforms.” In

Discourse Formation in Comparative Education, edited by Jürgen Schriewer, 4th ed., 155-187. Peter Lang.

Strang, David, and John W. Meyer. 1993. "Institutional Conditions for Diffusion." Theory and Society 22 (4): 487-511.

Tan, Jason. 2010. "Compulsory Education in Singapore-Who Benefits?" Asia Pacific Journal of Education 30 (4): 401-418.

Valente, Thomas W. 1995. Network Models of the Diffusion of Innovations. Cresskill, NJ: Hampton Press.

Vega Yon, G. \& Valente, T. W. 2021. netdiffuseR: Analysis of Diffusion and Contagion Processes on Networks, R package version 1.22.3, https://doi.org/ 10.5281/zenodo.1039317.

Wallerstein, Immanuel M. 2004. World-Systems Analysis: An Introduction. Durham: Duke University Press.

Weber, Max. 1972. Wirtschaft und Gesellschaft: Grundriß der verstehenden Soziologie. Tübingen: Mohr.

Weymann, Ansgar. 2014. States, Markets and Education: The Rise and Limits of the Education State. Palgrave Macmillan.

Windzio, Michael, and Kerstin Martens. 2021. "The Global Development, Diffusion, and Transformation of Education Systems: Transnational Isomorphism and 'Cultural Spheres'." In Global Pathways to Education: Cultural Spheres, Networks, and International Organizations, edited by Michael Windzio and Kerstin Martens, 1-35. London: Palgrave Macmillan.

World Conference on Education for All. 1990. Meeting Basic Learning Needs: A Vision for the 1990s: World Conference on Education for All Background Document. Inter-Agency Commission (UNDO, UNESCO, UNICEF, WORLD BANK) for the World Conference on Education for All. Last accessed March 2, 2021. http://www.unesco.org/education/information/pdf/11_92. pdf. 
Open Access This chapter is licensed under the terms of the Creative Commons Attribution 4.0 International License (http://creativecommons.org/ licenses/by/4.0/), which permits use, sharing, adaptation, distribution and reproduction in any medium or format, as long as you give appropriate credit to the original author(s) and the source, provide a link to the Creative Commons license and indicate if changes were made.

The images or other third party material in this chapter are included in the chapter's Creative Commons license, unless indicated otherwise in a credit line to the material. If material is not included in the chapter's Creative Commons license and your intended use is not permitted by statutory regulation or exceeds the permitted use, you will need to obtain permission directly from the copyright holder.

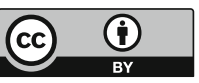

